\title{
The Effects of Percutaneous Atrial Septal Defect Closure on Cardiac Remodelling at Short and Intermediate Term Follow-up
}

\author{
Ali Hikmet Kirdok ${ }^{1}$, Efe Edem ${ }^{2 *}$ \\ ${ }^{1,2}$ Cardiology Department, Izmir Tinaztepe Hospital, Turkey
}

*Corresponding Author: Efe Edem, Cardiology Department, Izmir Tinaztepe Hospital, Turkey, Email: edemefe@gmail.com

\begin{abstract}
Background: Chronic right atrium $(R A)$-ventricul $(R V)$ volume overload and dilatation are well known consequences of atrial septal defect (ASD) and are associated with most of the long term complications. Percutaneous ASD closure has become an established therapy that is performed in increasing numbers of patients. The aim of this study was evaluate the effects of percutaneous closure procedure to right heart remodelling.
\end{abstract}

Methods: A retrospective original study was designed. Cardiac chambers were assessed by transthoracic echocardiography 1 st, $3 \mathrm{rd}$ and 6 th months after percutaneous closure in 88 patients. Mean age of the patients was $38.2 \pm 15.2$ years.

Results: There were significant reduction in right heart chamber dimensions and pulmonary artery pressure at 1st, 3rd and 6th month follow-up ( $p<0.001)$. By 6 months, left ventricular end diastolic dimension and left ventricular/right ventricular (LV/RV) diameter ratio increased when compared with pre-closure values (43.7 $\pm 3.7 \mathrm{~mm}$ vs. $44.5 \pm 3.9 \mathrm{~mm}, p=0.01 ; 1.1 \pm 0.2$ to $1.4 \pm 0.2$, $p<0.001$, respectively). The right chamber diameter reductions $(\Delta R A, \Delta R V)$ at 6month follow-up was associated with pre-closure right chamber diameters and cardiac remodelling was more pronounced in patients who have larger $R A$ and $R V$ dimensions pre-procedurally ( $r=0.59, p<0.01 ; r=0.59, p<0.01$, respectively).

Conclusions: Percutaneous ASD closure results in early cardiac geometric changes that may be beneficial during long-term follow-up and these changes occur within first months from ASD closure.

Keywords: Congenital and acquired defects, Intracardiac procedures, Percutaneous interventional procedures

\section{INTRODUCTION}

Isolated atrial septal defect (ASD) constitutes 7$11 \%$ of all congenital cardiac defects and is the most prominent cause of chronic volume loading of the right heart (1). A long volume loading may cause right heart failure, arrhythmia, thromboembolic events, and pulmonary vascular obstructive disease (2-4). Therefore, the main aims of ASD closure procedures include restoring the volume load on the right heart and preventing the possible negative impacts that may result from the volume load. Several studies have shown that the surgical closure procedure is usually ineffective for correcting cardiac geometry (59). This case was reportedly associated with certain causes, such as the surgical technique, effects of pericardiectomy, and contagion of echocardiographic measurements from standard images due to the changing position of the heart. Percutaneous closure has become an alternative treatment method of treatment for secundumtype ASD (10-11). Percutaneous closure may be considered as a more objective method than surgery for assessing the effects of the closure procedure on cardiac restoration (12). The aim of the present study was to assess the effects of the ASD closure procedure on restoring the right heart in the short- and mid-term periods.

\section{Material And Methods}

A total of 88 adult patients who successfully underwent the percutaneous ASD closure procedure in the cardiology clinic of a tertiary healthcare hospital between March 2007 and June 2016 were enrolled in the study.

All patients were assessed for defect diameter, defect rims, dimensions of the right and left 
cardiac cavities, and ventricular function via transthoracic and transoesophageal echocardiography (TOE) and the defect's eligibility for closure was determined. Furthermore, cardiac catheterisation was performed on each patient and the left to right shunt rate was assessed. Echocardiographic examinations were performed via a Vivid 3 echocardiography device (Vingmed Ultrasound, Norway). The dimensions of the left ventricle (LV) were obtained from the parasternal long axis view by the M-Mode method; furthermore, the end-diastolic dimensions of both ventricles were obtained from the apical fourchamber view. The dimensions of the right atrium (RA) and left atrium (LA) were assessed from the apical four-chamber view; the dimension of the LA was also assessed from the parasternal long axis view. Systolic pulmonary artery pressure (sPAP) was calculated from tricuspid failure jet through Bernoulli equation. The SPAP calculated via echocardiographic findings was accepted as indicative of slight pulmonary hypertension if $40-49 \mathrm{mmHg}$, moderate pulmonary hypertension if 50-59 $\mathrm{mmHg}$, and severe pulmonary hypertension if $\geq 60 \mathrm{mmHg}$.

The percutaneous ASD closure procedure was performed fluoroscopically and transthoracically or via TOE under general or local anaesthesia. Consent was obtained for the ASD closure procedure from each patient before the procedure. A percutaneous ASD closure procedure was performed as pre-defined in the literature (13). The procedure was started by insertion into the femoral vein; a carrier sheath sent over the guide wire was forwarded to the RA and then to the LA by passing through the ASD. Next, the LA disc of the occluder device sent inside the sheath was opened in the LA and leaned on the inter-atrial septum. After confirmation by echocardiography and fluoroscopy that the device was in the right position, the RA disc was opened and the device was placed into the defect area. After the procedure, clopidogrel was provided for the first 3 months and acetylsalicylic acid was provided for the first 6 months to all patients. Patients continued to use their ongoing therapy which was needed after the procedure and there were six patients whose therapy was including diuretics.

The following day as well as 1, 3, and 6 months after the procedure, all patients were assessed by transthoracic echocardiography and TOE, if necessary; the dimensions of the right and left cardiac chambers, pulmonary artery pressure, and valve and ventricle functions were examined; and the patients were examined for residual shunts.

\section{Statistical Analysis}

Continuous variables were defined as mean \pm standard deviation, while categorical variables were expressed as percentages. Analysis of variance and $\chi^{2}$ tests were used to compare continuous and categorical variables, respectively. Pearson's correlation analysis was run to determine the associated parameters. The results were evaluated within a 95\% confidentiality interval and significance was evaluated at values of $p<0.05$. Statistical analysis and calculations were performed using the Statistical Package for the Social Sciences for Windows 16.0 program.

\section{RESUlts}

A total of 88 patients (69 women [78\%]; mean age, $38.2 \pm 15.2)$ were enrolled. Of them, 78 $(90 \%)$ had a single defect, seven (8\%) had two defects, and two (2\%) had three defects in the inter-atrial septum. The mean diameter of the defect measured by TOE was $19.5 \pm 6.7 \mathrm{~mm}$. Slight (40-49 $\mathrm{mmHg}$ ) pulmonary hypertension was detected in $20 \%$ of the patients; moderate $(50-59 \mathrm{mmHg})$ pulmonary hypertension was detected in $3 \%$ of the patients; and severe $(\geq 60$ $\mathrm{mm} \mathrm{Hg}$ ) pulmonary hypertension was detected in $7 \%$ of the patients. The patients' demographic, echocardiographic, and catheter-related findings before the procedure are summarized in Table 1. The patients with a larger defect diameter had statistically greater RA and right ventricular $(\mathrm{RV})$ dilatation and pulmonary artery pressure $(\mathrm{r}=$ $0.33, \mathrm{p}<0.01 ; \mathrm{r}=0.31, \mathrm{p}<0.01 ; \mathrm{r}=0.36, \mathrm{p}<0.01$, respectively). Furthermore, a positive correlation was detected between age and RA and RV dimensions and pulmonary artery pressure $(\mathrm{r}=$ $0.44, \mathrm{p}<0.01 ; \mathrm{r}=0.43, \mathrm{p}<0.01 ; \mathrm{r}=0.38, \mathrm{p}<$ 0.01 , respectively).

Table1. Demographic and clinical characteristics of the study population.

\begin{tabular}{|l|l|}
\hline & $\mathbf{n = 8 8}$ \\
\hline Gender (female) & $\% 78(69)$ \\
\hline Age & $38.2 \pm 15.2$ \\
\hline $\begin{array}{l}\text { Diameter of the defect } \\
\text { measured by TEE (mm) }\end{array}$ & $19.5 \pm 6.7$ \\
\hline Sizing balloon (mm) & $20.8 \pm 6.4$ \\
\hline $\begin{array}{l}\text { Pre-procedural } \\
\text { sPAP(mmHg) }\end{array}$ & $27.8 \pm 6.4$ \\
\hline $\begin{array}{l}\text { Diameter of the device } \\
\text { (mm) }\end{array}$ & $23.8 \pm 6.5$ \\
\hline Qp/Qs & $1.9 \pm 0.2$ \\
\hline
\end{tabular}

TEE: Transesophageal echocardiography, sPAP: Systolic pulmonary artery pressure 
The Effects of Percutaneous Atrial Septal Defect Closure on Cardiac Remodelling at Short and Intermediate Term Follow-up

General anaesthesia was administered to $94 \%$ of the patients via TOE, while the remaining patients underwent the procedure under local anaesthesia with transthoracic echocardiography guidance. For the ASD occlusion, Amplatzer was used on 45 patients (51\%), Cardi-O-Fix on 29 patients (33\%), Bio STAR on five patients $(5.7 \%)$, SeraCare on five patients $(5.7 \%)$, and cribri form type Amplatzer on four patients $(4.5 \%)$. Of the patients with multiple defects, two devices were used on five (6\%) patients and one device was used on the others to close the defect. Home-made fenestrated devices has been recently suggested in the management of patients with pulmonary hypertension to avoid decompensated right heart failure however it was not needed to create such a device in our study. The discrepancy between balloon sizing and actual device size implanted might be remarkable in Table 1. Accurate device sizing to fit the dimensions of the defect is an important factor for the success and the safety of the method. The company recommends $1-2 \mathrm{~mm}$ but our cohort is 3-4 mm larger. However we did not detect any issues with erosions on follow up. Complete closure was detected in $99 \%$ of the patients; the minimal residual leakage observed in one patient after the procedure had regressed completely by the 1-month follow-up appointment. No major or minor complications were observed in any of the patients; however, during the procedure, two patients experienced a supraventricular tachycardia attack.

A significant decrease in the RA and $R V$ dimensions and pulmonary artery pressure was detected from 1 month after the closure procedure compared with the pre-procedural values (Table 2; Figures 1 and 2). Furthermore, a significant increase was observed in enddiastolic diameter of the $\mathrm{LV}$ as well as the LV/RV diameter ratio 6 months after the procedure compared with the pre-procedural values $(44.5 \pm 3.9 \mathrm{~mm}$ versus $43.7 \pm 3.7 \mathrm{~mm}$, $1.4 \pm 0.2, \mathrm{p}<0.001$ versus $\mathrm{p}=0.01 ; 1.1 \pm 0.2$ ).

Table2. Pre-procedural and follow-up $R A, R V$ dimensions and SPAP values of the study population.

\begin{tabular}{|l|l|l|l|l|l|}
\hline & $\begin{array}{l}\text { Pre- } \\
\text { proce } \\
\text { dural }\end{array}$ & $\begin{array}{l}\text { 1- } \\
\text { month } \\
\text { follow- } \\
\text { up }\end{array}$ & $\begin{array}{l}\text { 3- } \\
\text { month } \\
\text { follow- } \\
\text { up }\end{array}$ & $\begin{array}{l}\text { 6- } \\
\text { month } \\
\text { follow- } \\
\text { up }\end{array}$ & $\begin{array}{l}\text { p } \\
\text { valu } \\
\text { elu }\end{array}$ \\
\hline RA & $\begin{array}{l}40.8 \pm \\
6.9\end{array}$ & $\begin{array}{l}37.2 \pm 5 . \\
8\end{array}$ & $\begin{array}{l}35.3 \pm 5 . \\
5\end{array}$ & $\begin{array}{l}33.8 \pm 5 . \\
4\end{array}$ & $\begin{array}{l}\mathrm{p}<0 . \\
01\end{array}$ \\
\hline RV & $38.6 \pm$ & $34.8 \pm 6$. & $33.1 \pm 6$. & $31.4 \pm 5$. & $\mathrm{p}<0$. \\
& 7.2 & 2 & 2 & 7 & 001 \\
\hline SPA & $37.5 \pm$ & $32.4 \pm 8$. & $30.0 \pm 7$. & $27.8 \pm 6$. & $\mathrm{p}<0$. \\
P & 10.5 & 3 & 1 & 4 & 001 \\
\hline
\end{tabular}

RA: Right atrium, RV: Right ventricle, sPAP: Systolic pulmonary artery pressure

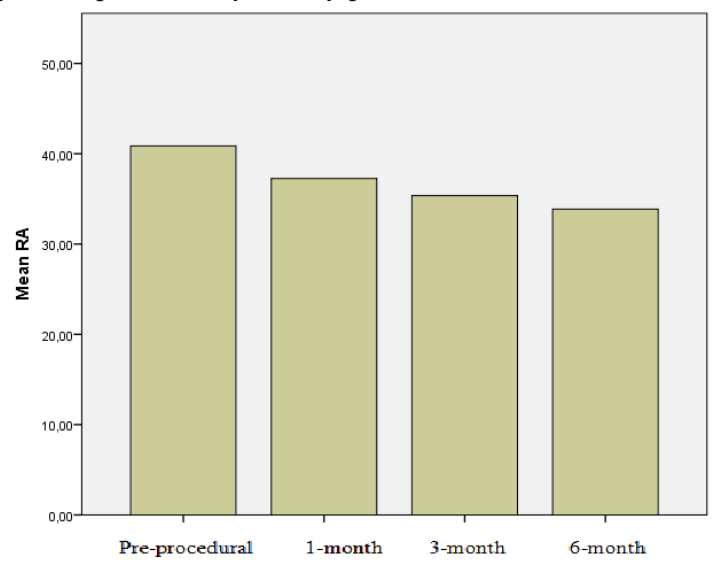

Figure1. Figure demonstrating the changes of mean rigt atrium (RA) dimensions in apical four chamber view before and after percutaneous ASD closure over time.

RA: Right atrium, ASD: Atrial septal defect

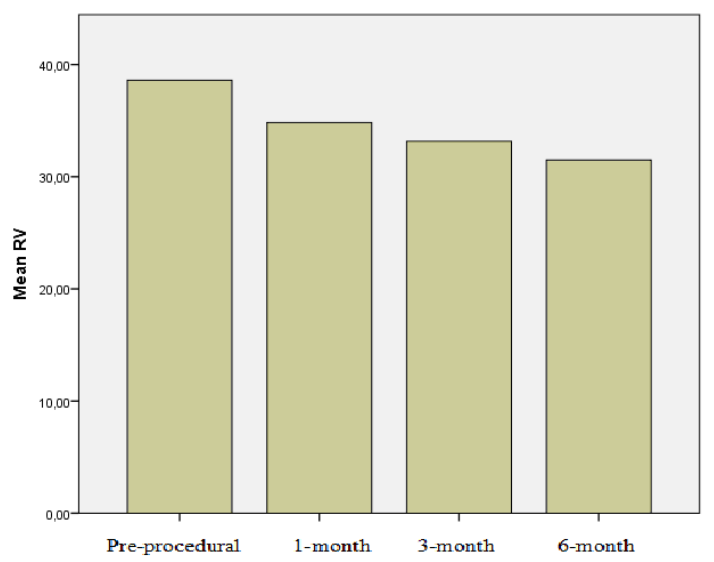

Figure2. Figure demonstrating the changes of mean ventricle $(R V)$ dimensions in apical four chamber view before and after percutaneous ASD closure over time.

\section{RV: Right ventricle, ASD: Atrial septal defect}

The reduction portion ( $\Delta \mathrm{RA}, \Delta \mathrm{RV})$ that appeared due to cardiac restoration in the RA and RV dimensions at the end of $6^{\text {th }}$ month associated with previous RA and RV dimensions and cardiac restoring after the procedure was more significant in the patients with a larger pre-procedural RA $(r=0.59, \mathrm{p}<$ $0.01 ; \mathrm{r}=0.59, \mathrm{p}<0.01$, respectively).

The sPAP was $>40 \mathrm{mmHg}$ in $31 \%(\mathrm{n}=27)$ of the patients. A significant decrease was detected in SPAP in this patient group at the 6-month follow-up compared with previous values (33.1 $\pm 7.7 \mathrm{mmHg}$ versus $49.4 \pm 10.5 \mathrm{mmHg}, \mathrm{p}<$ $0.01)$. The sPAP decreased within the normal range in all of the patients except one, who had 
slight pulmonary hypertension. Among the patients with moderate or severe pulmonary hypertension, the sPAP decreased to $<40 \mathrm{mmHg}$ in $56 \%$ of the patients within 6 months and decreased in other patients compared with the pre-procedural values; however, sPAP was also detected at $>40 \mathrm{mmHg}$.

\section{DISCUSSION}

ASD is the most common cause of chronic exposure of the RA and RV to volume load (13). Exposure of the right heart to a chronic volume load causes progressive RA and RV dilatation and may lead to the impairment of the ventricular functions as well as pulmonary hypertension (15-19). Therefore, the aims of ASD closure are to preserve cardiac function by reducing the volume load on the right heart and prevent the development of pulmonary vascular disease even when the patient is asymptomatic. This basic point was the denominator for attempted ASD closure over the study time period. Studies have shown that cardiac restoring results in a reduced dimension of the right heart and that recovery of the ventricular functions occurs in patients who underwent transcatheter ASD closure (20-22). Our findings were consistent with those of previous studies and a significant decrease was observed in RA and RV dimensions from the first month; a significant portion of such changes was observed within the first month, while it continued until the sixth month. Furthermore, an increase in $\mathrm{LV}$ dimensions and LV/RV ratio was observed. Thus, global cardiac restoring affecting both the right and left cardiac formations occurs after percutaneous ASD closure.

One study hypothesized that increasing the volume load and duration on the right formation may negatively affect cardiac restoring $(9,23-$ $25)$. In the present study, we detected that the reduction in RA and RV dimensions was more evident in the patients with a greater volume load and wider right heart dimensions despite this hypothesis. Although the data in the literature are conflicting, Santoro et al. compared two groups of patients who underwent an ASD closure procedure during childhood or adulthood for cardiac restoring and did not find any difference in terms of restoring proportion or duration (14). The findings of another study, consistent with those here, detected greater changes in the heart dimensions of patients with a higher volume load after closure; as such, the heart dimensions became normal or near-normal in those patients with a greater volume load (12). However, patients with ASD causing a severe haemodynamic left to right shunt flow without pulmonary hypertension were assessed in both studies. Therefore, the restoring process of the right heart exposed to a severe pressure load for a long period of time may differ. Likewise, in the study of Balint et al. that investigated the effects of percutaneous ASD closure procedure to pulmonary artery pressure in patients with moderate or severe pulmonary hypertension, the regression of $\mathrm{RV}$ findings in a significant proportion of patients during long-term followup was reported (26). Despite this, the RV dimensions remained normal in one third of the patients. Furthermore, although a significant regression was observed in mean patient sPAP values, the SPAP value did not decrease to normal limits in most of the patients. Similarly, we observed a significant decrease in SPAP in the patients with pulmonary hypertension; however, we detected that sPAP was still $>40$ $\mathrm{mmHg}$ in almost half of the patients with moderate or severe pulmonary hypertension at the end of 6 months.

It is known that pulmonary hypertension does not appear in all patients with ASD. Studies have reported a pulmonary hypertension prevalence in patients with ASD of 6-17\% (2628 ). It was suggested that the only factor of the development of obstructive pulmonary vascular disease in patients with ASD was not increased pulmonary flow (26). A significant yet weak correlation observed between the defect diameter and sPAP in the present study is thought to be that the only factor for the development of pulmonary hypertension was not left to right shunt portion.

\section{Conclusion}

The percutaneous ASD closure procedure has become a valuable and recognized alternative to surgical closure with a higher success rate and lower risk of complications. Our study results show that cardiac restoring occurs in patients who underwent percutaneous ASD closure from the early term and is more significant in patients with a wider right heart dimension due to an increased volume load. Although SPAP recovery was also observed in patients with pulmonary hypertension, larger-scale studies are required to determine treatment strategies in this patient group. 


\section{STUDY LIMITATIONS}

Data that we have are short- and mid-term results. The majority of patients who undergo percutaneous ASD closure procedure in our centre are referred from other cities, meaning that their long-term follow-up is generally performed in other centres. Therefore, we do not have long-term follow-up results of many of our patients. Furthermore, other causes that may lead to pulmonary hypertension in patients with pulmonary hypertension were not investigated in the present study and our study does not include hemodynamics and pulmonary vascular resistance calculations for the study cohort. We also did not have access to use cardiac magnetic resonance in our patients which could be a more accurate way to truly measure geometry in three-dimensional structures.

\section{REFERENCES}

[1] HD Allen, DJ Driscoll, RE Shaddy, TF Feltes. Atrial Septal Defects. "Moss \& Adams Heart Disease in Infants, Children, and Adolescent including the Fetus and Young Adult" (Ed. Allen HD, Gutgesell HP, Clark EB, Driscoll DJ )'da 6. bask1, Lippincott Williams and Wilkins, Philadelphia 2001,s.687-703

[2] Campbell M: Natural history of atrial septal defect. Br Heart J 1970, 32(6):820-6.

[3] Steele PM, Fuster V, Cohen M, DG Ritter, DC Mcgoon. Isolated atrial septal defect with pulmonary vascular obstructive disease - longterm follow-up and prediction of outcome after surgical correction. Circulation 1987, 76(5):103742.

[4] Jones HR Jr, Caplan LR, Come PC, Swinton NW Jr, Breslin DJ. Cerebral emboli of paradoxical origin. Ann Neurol 1983, 13(3):314-9.

[5] Pearlman AS, Borer JS, Clark CE, van Eickels M, Gaudin C, Torp-Pedersen C, et al. Abnormal right ventricular size and ventricular septal motion after atrial septal defect closure: etiology and functional significance. Am J Cardiol 1978; 41:295- 301.

[6] Meyer RA, Korfhageh JC, Covitz W, Kaplan S. Long-term follow-up study after closure of secundum atrial septal defect in children: an echocardiographic study. Am J Cardiol 1982; 50:143-8.

[7] Ning SB, Fazal H, Cook D, Wood MM, Duncan WJ, Rowe RD. Right ventricular size and ventricular septal motion after repair of atrial septal defect in children. Can J Surg 1984; 27:395-8.

[8] Ghosh S, Chatterjee S, Black E, Firmin RK. Surgical closure of atrial septal defects in adults: effect of age at operation on outcome. Heart 2002; 88:485- 7 .

[9] Attenhofer Jost CH, Oechslin E, Seifert B, Maly F, Fatio R, Turina J, et al. Remodelling after surgical repair of atrial septal defects within the oval fossa. Cardiol Young 2002; 12(6):506-12.

[10] Cowley CG, Lloyd TR, Bove EL, Gaffney D , Dietrich M, Rocchini AP. Comparison of results of closure of secundum atrial septal defect by surgery versus Amplatzer septal occluder. Am J Cardiol 2001; 88: 589-59

[11] Du ZD, Hijazi ZM, Kleinman CS, Norman H Silverman, Kinley Larntz. Investigators Amplatzer. Comparison between transcatheter and surgical closure of secundum atrial septal defect in children and adults: results of a multicenter nonrandomized trial. J Am Coll Cardiol 2002; 39: 1936-1944

[12] Pascotto M, Santoro G, Cerrato F, Caputo S, Bigazzi MC, Iacono C. Time-course of cardiac remodeling following transcatheter closure of atrial septal defect. Int Journal Cardiol 112 (2006) $348-352$

[13] Masura J, Gavora P, Formanek A, Hijazi ZM. Transcatheter closure of secundum atrial septal defects using the new self-centering Amplatzer septal occluder: initial human experience. Cathet Cardiovasc Diagn 1997; 42:388 -93

[14] Santoro G, Pascotto M, Caputo S, Cerrato F, Bigazzi MC, Palladino MT, et al. Similar cardiac remodelling after transcatheter atrial septal defect closure in children and young adults. Heart 2006;92:958 -962.

[15] Giardini A, Donti A, Formigari R, Specchia S, Prandstraller D, Bronzetti $G$, et al. Determinants of cardiopulmonary functional improvement after transcatheter atrial septal defect closure in asymptomatic adults. J Am Coll Cardiol 2004; 43:1886 -1891.

[16] Morton JB, Sanders P, Vohra JK, Sparks PB, Morgan JG, Spence SJ, et al. Effect of chronic right atrial stretch on atrial electrical remodeling in patients with an atrial septal defect. Circulation 2003; 107:1775-82.

[17] Ascah KJ, King ME, Gillam LD, Weyman AE. The effects of right ventricular hemodynamics on left ventricular configuration. Can J Cardiol 1990;6: 99-106.

[18] Walker RE, Moran AM, Gavreau K, Colan SD. Evidence of adverse ventricular interdependence in patients with atrial septal defects. Am J Cardiol 2004; 93:1374-7.

[19] Brochu MC, Baril JF, Dore A, Juneau M, De Guise P, Mercier LA. Improvement in exercise capacity in asymptomatic and mildly symptomatic adults after atrial septal defect 
percutaneous closure. Circulation 2002;106: 1821-6.

[20] Giardini A, Donti A, Specchia S, Formigari R, Oppido G, Picchio FM. Long-term impact of transcatheter atrial septal defect closure in adults on cardiac function and exercise capacity. Int J Cardiol 2008;124:179-182.

[21] Schoen SP, Kittner T, Bohl S, M U Braun, G Simonis, A Schmeisser, et al. Transcatheter closure of atrial septal defects improves right ventricular volume, mass, function, pulmonary pressure, and functional class: a magnetic resonance imaging study. Heart 2006; 92:821826.

[22] Salehian O, Horlick E, Schwerzmann M, Haberer K, McLaughlin P, Siu SC, et al. Improvements in cardiac form and function after transcatheter closure of secundum atrial septal defects. J Am Coll Cardiol 2005; 45:499 -504 .

[23] Murphy JG, Gersh BJ, McGoon MD, Mair DD, Porter CJ, Ilstrup DM, et al. Long-term
Outcome after surgical repair of isolated atrial septal defect. Follow-up at 27 to 32 years. N Engl J Med. 1990 Dec 13; 323(24):1645-50.

[24] Du ZD, Cao QL, Koenig P, Heitschmidt M , Hijazi ZM. Speed of normalization of right ventricular volume overload after transcatheter closure of atrial septal defect in children and adults. Am J Cardiol. 2001 Dec 15; 88(12): 1450-3.

[25] Kort HW, Balzer DT, Johnson MC. Resolution of right heart enlargement after closure of secundum atrial septal defect with transcatheter technique. J Am Coll Cardiol. 2001 Nov 1; 38(5):1528-32.

[26] Balint OH, Samman A, Haberer K, Tobe L, McLaughlin P, Siu SC, et al. Outcomes in patients with pulmonary hypertension undergoing percutaneous atrial septal defect closure. Heart. 2008 Sep; 94(9):1189-93.

[27] Craig RJ, Selzer A. Natural history and prognosis of atrial septal defect. Circulation 1968; 37: 805-15.

Citation: Ali Hikmet Kirdok, Efe Edem. The Effects of Percutaneous Atrial Septal Defect Closure on Cardiac Remodelling at Short and Intermediate Term Follow-up. ARC Journal of Cardiology. 2018; 4(1) 611. doi: dx.doi.org/11.20431/2455-5991.0401003.

Copyright: () 2018Authors. This is an open-access article distributed under the terms of the Creative Commons Attribution License, which permits unrestricted use, distribution, and reproduction in any medium, provided the original author and source are credited. 